\title{
COMPARING METHODS FOR IMPUTING EMPLOYER HEALTH INSURANCE CONTRIBUTIONS IN THE CURRENT POPULATION SURVEY
}

\author{
by
}

\author{
Hubert Janicki \\ U.S. Census Bureau
}

Brett O'Hara

U.S. Census Bureau

Alice Zawacki

U.S. Census Bureau

\begin{abstract}
CES 13-41
August, 2013

The research program of the Center for Economic Studies (CES) produces a wide range of economic analyses to improve the statistical programs of the U.S. Census Bureau. Many of these analyses take the form of CES research papers. The papers have not undergone the review accorded Census Bureau publications and no endorsement should be inferred. Any opinions and conclusions expressed herein are those of the author(s) and do not necessarily represent the views of the U.S. Census Bureau. All results have been reviewed to ensure that no confidential information is disclosed. Republication in whole or part must be cleared with the authors.

To obtain information about the series, see www.census.gov/ces or contact Fariha Kamal, Editor, Discussion Papers, U.S. Census Bureau, Center for Economic Studies 2K132B, 4600 Silver Hill Road, Washington, DC 20233, CES.Papers.List@census.gov.
\end{abstract}




\begin{abstract}
The degree to which firms contribute to the payment of workers' health insurance premiums is an important consideration in the measurement of income and for understanding the potential impact of the 2010 Affordable Care Act on employment-based health insurance participation. Currently the U.S. Census Bureau imputes employer contributions in the Annual Social and Economic Supplement of the Current Population Survey based on data from the 1977 National Medical Care Expenditure Survey. The goal of this paper is to assess the extent to which this imputation methodology produces estimates reflective of the current distribution of employer contributions. The paper uses recent contributions data from the Medical Expenditure Panel Survey-Insurance Component to estimate a new model to inform the imputation procedure and to compare the resulting distribution of contributions. These new estimates are compared with those produced under current production methods across employee and employer characteristics.
\end{abstract}

Keyword: health insurance, employer contributions, healthcare reform 


\section{Introduction}

The majority of Americans receive health insurance coverage from their employer. ${ }^{1}$ Changes in this system, however, were introduced in the Patient Protection and Affordable Care Act (ACA) in March 2010. The ACA introduced additional insurance purchasing options in the form of health insurance exchanges, expansions in eligibility for Medicaid, and penalties to certain employers that fail to offer health insurance coverage. ${ }^{2}$ Most of the ACA changes will occur in 2014, but knowledge of the potential impact of these changes in the employer-sponsored health insurance (ESI) system based on current data is informative. These provisions may affect decision making by both workers and their employers regarding health insurance coverage and the degree to which employers contribute towards health insurance premiums (Garrett \& Buettgens, 2011).

In addition, the degree to which firms contribute to the payment of workers' health insurance premiums is an important consideration in the measurement of income and poverty. The measurement of income by the U.S. Census Bureau traditionally relied on "money" income. However, Burtless and Savon (2010) and Burkhouser et al. (2012) find the inclusion of employment health insurance contributions has a marked effect on inequality in the U.S income distribution. Therefore, better estimates of employer contributions have the potential to improve measures of income by incorporating compensation in the form of employment-based health benefits.

While employer contributions for health insurance are not collected in the Annual Social and Economic Supplement of the Current Population Survey (CPS ASEC), the U.S. Census Bureau provides estimates of contributions based on the 1977 National Medical Care Expenditure Survey (NMCES). Because the CPS ASEC has a large enough sample size, state estimates of employer contributions can be made. These state-to-state differences are significant in the provision for employer-sponsored contributions (Shen \& Zuckerman, 2003). However, existing surveys, such as the MEPS Household Component, are unable to provide these data due to insufficient sample sizes. The goal of this paper is to assess the extent to which the current estimates of employment health insurance contributions constructed in the CPS ASEC reflect the distribution of contributions that is obtained using data that are more recent. This paper uses contributions data from the 2010 Medical Expenditure Panel Survey-Insurance Component (MEPS-IC) to estimate a new imputation model and to compare the resulting distribution of contributions.

This paper begins by describing the CPS ASEC, MEPS-IC, and NMCES data. The next section presents both the NMCES- and MEPS-IC based methods to estimate employer contributions. This is followed by a comparison of estimated contributions between the two series for nonFederal workers. In addition, we produce and evaluate estimates for Federal workers under an

155.1 percent of the U.S. population had employment-based health insurance coverage in 2011. (DeNavas-Walt et al., 2012)

${ }^{2}$ The 2010 ACA PL111-148 text is available from http://www.gpo.gov/fdsys/pkg/PLAW-111publ148/pdf/PLAW111publ148.pdf. 
experimental method and for individual states. The impact of top-coding is also addressed. The paper ends with concluding remarks.

\section{Data}

The CPS ASEC is a survey of approximately 78,000 households (i.e., about 100,000 addresses) and a single respondent within the household responds to the survey questions for all people in the household. ${ }^{3}$ This survey collects detailed health insurance data. Respondents are asked to report health insurance coverage status in the previous calendar year for themselves and all other household members. More specifically, respondents are asked if they or anyone in the household was covered by a health insurance plan provided by a current or former employer or union (HIEMP) and whether they are the policyholder (HIOWN) and whether employees purchase single or family coverage (HITYP). Respondents are asked to report whether additional persons within the household (DEPHI) or outside the household (HIOUT) are also covered under the ESI plan. The CPS ASEC does not collect information on plus-one health insurance plans (i.e., a plan that covers the policyholder and one additional person). For the purposes of our estimation, we treat policyholders with one additional person covered as policyholders of a plus-one health insurance plan. In addition, the CPS ASEC asks if the employer pays all, part, or none of the health insurance premium (HIPAID) and the amount of the employee health insurance premium payment (PHIP_VAL). ${ }^{4}$

We match employer data from the 2010 MEPS-IC with individual data from the 2011 CPS ASEC, since the 2010 MEPS-IC is collected under a current year design and the CPS ASEC asks about insurance coverage in the previous year. We only use individuals who are employed and the policyholder for an ESI-plan reporting a positive employer contribution. We do not impute employer contributions for policyholders in the CPS ASEC who report that the employer does not contribute toward ESI coverage. In addition, self-employed workers and workers without pay are excluded from our analysis, since these individuals would generally purchase insurance coverage in the individual market if not covered under another person's policy (e.g., a spouse's health plan). ${ }^{5}$

CPS ASEC data collected on employee and employer contributions are sometimes inconsistent (see Table 1). First, 4.5 percent of all policyholders report a positive out-of-pocket contribution towards premium costs but also report that the employer pays the entire premium cost. Second, 21.7 percent of all policyholders report no out-of-pocket premium contribution but also report that the employer pays some or none of the cost. We reconcile these inconsistencies by relying on the lack of measurement error in the discrete response to the employer contribution (all, part, none) and assume inconsistent responses in employee contributions are due to measurement error. If respondents report the employer pays the entire premium cost, we set the employee contribution to zero. If respondents report the employer pays some or none of the premium cost, we use hot decking imputation methods to obtain a consistent value of the employee

\footnotetext{
${ }^{3}$ Data are subject to error arising from a variety of sources. For more information on sampling and non-sampling error, see www.census.gov/apsd/techdoc/cps/cpsmar11.pdf (accessed May 14, 2013).

${ }^{4}$ Addressing other ACA-related measures, such as income and full- or part-time work status, is outside the scope of the current paper.

${ }^{5}$ Sampled establishments in the MEPS-IC have at least one paid employee.
} 
contribution. After setting the reported value to missing, we assign a value from an individual in the matched sample with similar economic characteristics (i.e., industry classification and whether the respondent paid some or none of the health insurance premium). ${ }^{6}$

The U.S. Census Bureau, under sponsorship by the Agency Healthcare Research and Quality (AHRQ), collects the MEPS-IC. A repeated cross-sectional annual survey, the MEPS-IC has a nationally-representative sample of about 30,000 private establishments. Data are also collected from employers in state and local governments. The sampling frame for private employers and government units is the U.S. Census Bureau's Business Register (BR), formerly the Standard Statistical Establishment List and the Government Integrated Directory, respectively. ${ }^{7}$ The MEPS-IC asks whether health insurance is offered through the employer or union and requests detailed health plan information if ESI is offered. The survey also includes employer and workforce characteristics.

In addition to employer and employee contributions towards health insurance premium costs, the MEPS-IC collects data on total premiums, enrollment, out-of-pocket costs (deductibles, copayments) and provider arrangement for plans with single, plus-one, and family coverage. ${ }^{8}$ Detailed information on health insurance plans offered by employers in the private sector is limited to four plans (i.e., three largest plans in terms of enrollment are selected and fourth plan is randomly selected). Plan information is collected on all ESI plans offered by state and local governments.

We use regression-based statistical matching to assign employers to workers found in the CPS ASEC. This requires data from both surveys on whether the employer paid part of the premium, the amount contributed by the employee, and the type of coverage (single, plus-one, and family). We use MEPS-IC data on premiums and employer contributions (continuous measure in MEPSIC) to identify whether the employer paid part or the entire ESI premium.

The data elements common to both the MEPS-IC and CPS ASEC and required by the regressionbased statistical matching also include firm size, industry, and location. Since the variable construction varies across the two datasets, we take the following steps to make the definitions uniform. First, firm size in the MEPS-IC is categorized into one of the six categories defined in the CPS ASEC and reflects firm employment. ${ }^{9}$ The six categories are defined as less than 10, 10-49, 50-99, 100-499, 500-999, and 1000+ employees. The industry classification for each MEPS-IC establishment is categorized according to the major industry recode found in the CPS ASEC (page A-11 of the CPS technical documentation). Industry information is not available for plans offered by state and local government units in the MEPS-IC and is excluded from the imputation procedure. Establishment location is defined by nine Census regions defined in the CPS ASEC technical documentation (pages 9-13).

\footnotetext{
${ }^{6}$ Using additional characteristics (e.g., firm size) leads to empty donor cells.

${ }^{7}$ All state governments and local governments with more than 5,000 full-time equivalent employees are always sampled.

${ }^{8}$ The MEPS-IC also asks whether the plan covers physician care and whether hospital care is covered. Only plans covering both physician and hospital care are used in our analyses.

${ }^{9}$ An establishment refers to the location where business activity takes place. A firm represents one or more establishments under common ownership.
} 
The CPS ASEC currently contains estimates for employer contributions based on a model using the 1977 NMCES. This household survey of about 14,000 households was sponsored by the National Center for Health Services Research (now (AHRQ) and collected by the Research Triangle Institute. The NMCES and MEPS represent the first and third survey in a series of national surveys conducted by AHRQ on the financing and use of medical care in the United States. ${ }^{10}$ The NMCES provides information on individual health expenditures, financing, and utilization of medical care. Employer contributions towards premium costs for ESI were obtained through supplemental interviews with individual employers through the Health Insurance/Employer Survey. ${ }^{11}$

\section{Estimating Employer Contributions}

\section{Using the NMCES}

The current estimates of employer contributions (EMCONTRB) in the CPS ASEC grew out of an effort to create an experimental poverty measure that incorporated non-cash benefits (U.S. Census Bureau, 1982) and the procedure is described in Measuring the Effect of Benefits and Taxes on Income and Poverty: 1990 (U.S. Census Bureau, 1991). This method for constructing employer contributions in the CPS ASEC imputes values using data from the 1977 NMCES for non-Federal workers. ${ }^{12}$ In the first step of the imputation procedure, the 1977 NMCES and the 1980 CPS ASEC were statistically matched using available demographic and economic variables common to both surveys thereby creating measures for total earnings and hours (full-time and part-time) in the NMCES data.

Next, this matched dataset was used to estimate a linear regression model of employer contributions regressed on a set of covariates available in both datasets. These covariates include industry, occupation, Census region, coverage type (single or family), sector (private or government), residence, individual earnings, hours (full-time and part-time), age, race, marital status, education, and whether the employer pays all or part of the health insurance premium. Finally, the estimated model is used to generate values for any year of the CPS ASEC. To generate measures of employer contributions in year $t$, individual earnings in year $t$ are deflated to 1977 using the CPI for all consumers (all items less food and energy). The relevant model coefficients are then used to generate values of the contributions in 1977 dollars. These

\footnotetext{
${ }^{10}$ AHRQ sponsored the National Medical Expenditure Survey (NMES) in 1987, which is the second survey in this series.

${ }^{11}$ Documentation for the NMCES is available from $h t t p: / / d x . d o i . o r g / 10.3886 / I C P S R 08627 . v 1$.

${ }^{12}$ Employer contributions for Federal employees are imputed using annualized monthly contributions for postal and non-postal employees using OPM administrative data that are then adjusted for part-time employment and type of coverage (single or family).
} 
contributions are then inflated to year $t$ dollars using a price index of average contributions per enrolled worker. ${ }^{13}$

\section{Using the MEPS-IC}

The procedure used in this study to impute employer contributions onto the CPS ASEC using the MEPS-IC relies on a regression-based method similar to predicted mean matching (Rubin, 1987), where employer contributions are linearly regressed on a set of covariates common to both the MEPS-IC and the CPS ASEC. ${ }^{14}$ Employers from the MEPS-IC are matched to employed CPS ASEC respondents who are ESI-policyholders with employers making positive contributions towards premiums using employer characteristics common to both surveys. Values of employer contributions are drawn from the posterior predictive distribution (PPD) implied by the regression parameters and the covariance matrix derived from the MEPS-IC. Sometimes the PPD is less than or equal to zero. In this case, we take another draw from the PPD until there is a positive draw. In comparison, predicted mean matching relies on a draw of employer contributions from the set of observed values closest to the predicted value. By relying on simulated contribution estimates rather than reported values, we minimize the risk of disclosure of information and maintain privacy of respondents.

The first step of the imputation procedure creates a set of variables common to both the MEPSIC and the CPS ASEC that will serve as covariates in the regression. ${ }^{15}$ These include the number of employees, industry, state, coverage type (single, plus-one, family), sector (private and state and local governments), and whether the employer pays all or part of the health insurance premium and the employee contribution. ${ }^{16}$ After creating a stacked dataset with common variables, we use the PROC MI procedure in SAS to impute employer contributions for respondents in the 2011 CPS ASEC sample. ${ }^{17}$ The regression procedure is run separately for each type of coverage (i.e., single, plus-one, and family) and by whether the employer contributes all or part of the health insurance premium cost. The procedure allows for simulated contribution values that fall outside a reasonable range (i.e. negative contributions). In such cases, we allowed the algorithm to draw multiple values and use the first positive value.

\section{Comparing Estimated Employer Contributions}

\section{Non-Federal Workers}

\footnotetext{
${ }^{13}$ This price index is created by calculating current year employer contributions to group health insurance per enrollee from the BEA National Income and Product Accounts and dividing by average employer contributions per worker in 1977.

${ }^{14}$ In future work, consideration will be given to bounding the estimates although the estimated distribution shows few employer contributions in the tails.

${ }^{15}$ Due to restricted data access, we omit workers from the Federal Government from this part of our analysis but discuss these contributions below. Federal workers are omitted from this part of the analysis since the MEPS-IC does not collect data on health insurance provided to Federal workers. Our method here relies upon using and comparing similar data.

${ }^{16}$ CPS ASEC collects the state of residence, while MEPS-IC records the state where the employer is located. There is the possibility that state of residence and employment are not always the same, but we do not address this potential inconsistency.

${ }^{17}$ Detailed documentation on this multiple imputation procedure is available from the SAS Institute at http://support.sas.com/documentation/onlinedoc/stat/930/mi.pdf
} 
In this section, we present our main results that compare employer contributions by NMCESand MEPS-IC based imputation methods along demographic and economic characteristics of policyholders. The median values presented in this section are based on the population of nonFederally employed individuals, who are policyholders of a health insurance plan purchased through their employer and report that their employer paid for all or some of the health insurance premium. Estimates of employer contributions are top-coded at $\$ 9,999$, which is consistent with current U.S. Census Bureau data for this series. ${ }^{18}$ An interpolated median is calculated as per Census practice. All comparative statements are statistically significant at the 10 percent level.

Table 2 shows the median employer contribution by policyholder or employee characteristics. The median annual employer contribution in 2010 was significantly higher at \$6,159 using the MEPS-IC when compared to $\$ 5,444$ obtained using the original NMCES-based imputation. ${ }^{19}$ While private sector contributions were economically comparable (but statistically different) across imputation methods (\$5,793 vs. \$5,512), state/local government workers had dramatically higher median contributions when contributions were estimated using the MEPS-IC (\$7,663 vs. $\$ 5,214)$.

Table 2 shows the values of contributions also varied by the demographic and economic characteristics of policyholders. Median contributions using either the NMCES or MEPS-IC were higher for men than women, but the magnitude was smaller when using the MEPS-IC. Median contributions by race and ethnicity using the MEPS-IC were also greater than those constructed using the NMCES. For example, while the median contribution level among nonHispanic Blacks was $\$ 4,541$ using the NMCES, the MEPS-IC based imputation resulted in a significantly larger value of $\$ 5,948$. We also find median contributions between non-Hispanic Whites and Hispanics were statistically unchanged using the NMCES or the MEPS-IC. Median contributions among Hispanics were statistically unchanged from non-Hispanic Blacks using the MEPS-IC, but larger for Hispanics using the NMCES.

In addition, differences in contribution values varied across age categories for the policyholder by imputation method. For example, individuals age 19-25 had a median contribution of \$3,257 using the NMCES and \$4,641 using the MEPS-IC. Among individuals age 45 to 64, the median contribution value using the NMCES was \$5,699, while the contributions increased to \$6,364 using the MEPS-IC. The median contribution level across all educational groups was higher when calculated using the MEPS-IC rather than the NMCES. Median contributions using either method were lowest among those without at least a Bachelor's degree. Likewise, we find the median contributions among those with a Master's degree or higher had the highest median contribution levels at \$6,978 using the MEPS-IC and \$6,487 using the NMCES.

Finally, median contributions were highest for workers with family incomes 400 percent and above of the federal poverty threshold. Using the MEPS-IC and NMCES to calculate contributions, the median values were $\$ 6,662$ and $\$ 6,218$, respectively. In addition, respondents with family incomes less than 100 percent of the Federal poverty threshold had larger contributions using the MEPS-IC at \$5,991 when compared to the NMCES-based method at

\footnotetext{
${ }^{18}$ Future work will consider raising this threshold given the estimates using the MEPS-IC. The goal with the current exercise is to keep the estimates using the MEPS-IC as comparable as possible to those produced using the NMCES.

${ }^{19}$ Standard errors in the tables are based on publicly available replicate weights for the CPS.
} 
$\$ 3,773$. Among those with family incomes $200-299$ percent of the poverty threshold, the median contributions obtained using the MEPS-IC and NMCES were \$5,931 and \$4,469, respectively.

While the population characteristics listed in Table 2 represent basic demographic and economic variables of interest, with the exception of class of worker, these variables were not used in the revised MEPS-IC imputation method. The MEPS-IC is a survey of establishments and does not contain these data for workers. Instead, the imputation procedure relies on other covariates that are presented in Tables 3 and 4 and include location, industry, and firm size. Employer contributions were stratified by type of coverage: single, plus-one, and family. Table 3 provides estimates for single coverage plans. While plus-one and family coverage contributions were estimated separately, for ease of exposition we calculate medians from a pooled dataset of plusone and family plans in Table $4 .^{20}$

Contribution levels were higher among firms that paid the entire premium than those that only covered part of the premium for both single and combined plus-one/family coverage plans. Among employers that paid the entire health insurance premium, the median contribution using the MEPS-IC was $\$ 5,327$ for single plans and $\$ 9,815$ for plus-one/family plans. Using the NMCES, those values were $\$ 5,230$ and $\$ 9,217$, respectively. In contrast, among employers that paid only part of the health insurance premium, the median contribution using the MEPS-IC was $\$ 3,849$ for single plans and $\$ 8,563$ for plus-one/family plans. Using the NMCES, the values were $\$ 2,784$ and $\$ 6,639$ for single and plus-one/family plans, respectively.

Private sector workers have lower median contributions than local and state government workers using the MEPS-IC for single coverage plans. Differences between the class of worker were not statistically significant for single coverage plans using the NMCES. In the plus-one/family coverage plans, private sector employees had lower median contributions than state and local workers using the MEPS-IC, the reverse was true for the NMCES-based series.

Median contributions using the MEPS-IC and NMCES varied by location for both single and plus-one/family plans. For ease of exposition, we summarize these differences here by Census region (See the following section on state-specific differences). Median employer contributions in each Census region were larger using the MEPS-IC compared to those estimated using the NMCES for single plans with the exception of New England and Pacific regions. In addition, median contributions for combined plus-one/family plans increased in the MEPS-IC based imputation relative to using the NMCES-based imputation method in all regions. For example, single coverage premiums in the East-south-central region increased from \$1,992 to \$3,935 for single coverage, and increased from $\$ 5,552$ to $\$ 7,985$ for plus-one/family coverage.

By industry, there are significant differences in median contributions by imputation method and by type of coverage. Median contributions for single plans in public administration were $\$ 5,476$ using the MEPS-IC and \$3,784 using the NMCES. In comparison, median contributions for plus-one/family plans in public administration were \$9,152 using the MEPS-IC and \$7,187 using the NMCES. In addition, differences in median contributions in manufacturing for single

\footnotetext{
${ }^{20}$ A limitation in the case of non-Federal workers is that this pooling deflates the estimates, although not all firms offer this level of coverage. Estimates for Federal workers presented from our experimental approach and discussed below, are unaffected since plans with plus-one coverage are not offered.
} 
coverage plans were smaller using the MEPS-IC than in the NMCES-based method. In contrast, employer contributions for plus-one/family coverage were larger using the MEPS-IC $(\$ 9,788)$ versus using the NMCES $(\$ 7,874)$.

Contributions in the largest firm size category (1000+ workers) were larger using the MEPS-IC at $\$ 9,354$ compared to $\$ 7,069$ using the NMCES for plus-one/family coverage plans. In addition, median contributions among single coverage plans were larger for this size category in the NMCES-based method than the MEPS-IC based method. Among single coverage plans, the smallest firm ( $<10$ employees) had median contributions that were statistically different from the largest firms (1000+ employees) using NMCES, but statistically unchanged using the MEPS-IC. Among plus-one/family plans the largest employers had larger contributions than the smallest employers using the MEPS-IC at \$9,354 and \$8,193, respectively. In contrast, differences in contributions for plus-one/family coverage using the NMCES were statistically unchanged across these size groups.

\section{State-Specific Contributions}

There are significant differences in median contributions among states as seen in Table 5. Median contributions are statistically different between the MEPS-IC based and the NMCESbased method for all but fifteen states. ${ }^{21}$ We observe the largest median contributions in the MEPS-IC based imputation in Alaska at \$8,713, where the median contribution increased from \$6,144 in the NMCES-based imputation. The lowest median contribution in the MEPS-IC based method is Arkansas at $\$ 4,168$. Median contributions in Arkansas were smaller in the NMCESbased method than those obtained using the MEPS-IC. Hawaii is the only state with smaller median employer contributions using the MEPS-IC $(\$ 4,822)$ versus using the NMCES $(\$ 5,609)$.

\section{Federal Workers}

The above analysis excludes Federal workers due to the lack of data availability in the MEPS-IC. We experiment by allowing the imputation algorithm to treat Federal workers found in the CPS ASEC as private sector workers from the largest firms (1000+ employees) and impute their employer contributions accordingly from the pool of private sector establishments. This experiment is based on evidence that both the Federal government and most large private employers provide similar types of noncash compensation, such as retirement benefits, health insurance, and paid leave (Congressional Budget Office, 2012). Since the Federal government does not offer plus-one coverage, we eliminate this category of coverage from our imputation method.

As seen in Table 6, median contributions among Federal employees are substantially smaller using the MEPS-IC $(\$ 8,276)$ compared to using the NMCES $(\$ 9,006)$. According to Mach (2013), maximum Federal contributions range from $\$ 4,962$ to $\$ 11,049$ for single and family coverage plans, respectively. The estimates presented here fall within this range. By type of coverage, the results show no statistically significant change in single coverage contributions and an increase in family coverage contributions. In particular, while median contributions for

\footnotetext{
${ }^{21}$ Contributions are statistically unchanged between methods in Arizona, Illinois, Indiana, Kansas, Massachusetts, Michigan, Minnesota, Missouri, North Dakota, Ohio, Oregon, Rhode Island, South Dakota, Vermont, and Washington. .
} 
family coverage using the MEPS-IC increase to $\$ 9,809$ from $\$ 9,127$ using the NMCES, median contributions for single coverage are statistically unchanged at $\$ 4,296$ and $\$ 4,389$, respectively.

The median contribution among male Federal employees remained statistically unchanged across imputation methods, while for women the median contributions are higher using these same data (\$7,268 vs. \$5,653). Median contributions for Black Non-Hispanics and Hispanics are statistically unchanged for the MEPS-IC and NMCES methods. By education, median contributions are statistically unchanged across the imputation methods for workers across education groups. Large standard errors on median contributions in the NMCES-based imputation relative to the MEPS-IC based imputation for certain Census regions suggest that estimates obtained using the latter are more precise. However, from the calculated t-statistics we cannot infer changes in median contributions across Census regions.

\section{Top-Coding}

Estimated contributions using the MEPS-IC are top-coded at \$9,999 to maintain consistency with the NMCES-based method. Nevertheless, we find median contributions among nonFederally employed policyholders with family coverage are $\$ 9,815$. This suggests that close to 50 percent of respondents in this group have top-coded contribution amounts. In this section, we explore the extent to which the current top-coding threshold impacts the distribution of employer contributions obtained using the MEPS-IC.

Table 7 details the mean and standard deviation of ESI employer contributions by coverage type using the MEPS-IC by top-coding status. The table illustrates a statistically significant difference in means and standard deviations for all types of coverage combined as well as by each coverage type. For example, mean contributions among single plans were $\$ 4,246$ with the top-code and $\$ 4,252$ with the top-code removed. In contrast, mean contributions for family plans were $\$ 8,555$ with the top-code and $\$ 10,696$ without the top-code. This disparity suggests that the top-code has a larger effect on mean contributions for family plans than single coverage plans.

An even more striking comparison of the effects of top-coding can be seen in a comparison of the standard deviation of employer contributions. In particular, while removal of the top code increases the standard deviation among single plans from $\$ 2,543$ to $\$ 2,568$, the effect on family plans is even larger. Family plans subject to top-coding have a standard deviation of contributions at $\$ 2,539$, but $\$ 5,159$ with the top-code removed. While top-coding has no effect on the median values presented in the earlier analysis, the analysis presented in this section demonstrates the degree to which other commonly used estimates can vary by top-coding status. The U.S. Census Bureau is currently working to revise the series on employer contributions for health insurance. Should the MEPS-IC based series examined in this paper be put into production, a new top-code appropriate to the MEPS-IC based imputation will need to be introduced to reduce the potential bias associated with top-coding for public use files. Furthermore, implementation of this imputation procedure would rely on availability of MEPSIC data that would make price adjustment in the NMCES-based method unnecessary.

\section{Conclusion}


In this paper, we have shown significant differences in median contribution levels by imputation method. While median contributions among all non-Federally employed workers have increased substantially from $\$ 5,444$ to $\$ 6,159$, contributions among Federal workers have fallen using the MEPS-IC based method relative to the original NMCES-based method from \$9,006 to \$8,276. In addition to changes in levels of contributions among all policyholders, the results of this paper demonstrate striking differences in contributions by both employee and employer characteristics.

There are several avenues for future research. While the goal of this paper was largely to document the distribution of employer contributions resulting from a MEPS-IC based imputation, we feel subsequent work should explore the implications of this new series for income measurement and analysis of health care reform. For example, what are the quantitative implications of changes in the imputation of employment-based contributions for estimates of income inequality? Since low-income workers may receive benefits through ACA-related Medicaid expansions, will employers with predominantly low-income workers continue to contribute toward their employees' health insurance premiums? How will the opportunity to purchase health insurance through an exchange impact the degree to which employers offer health insurance and their contribution level? We leave these and many more questions for future papers. 


\section{References}

Burkhauser, R., Larrimore, J., and Kosali S., "Measuring the Impact of Health Insurance on Levels and Trends in Inequality and How the Affordable Care Act of 2010 Could Affect Them”, Contemporary Economic Policy, (2012)

Burtless, G. and Svaton, P., "Health Care, Health Insurance, and the Distribution of American Incomes,” Forum for Health Economics \& Policy, vol. 13, no. 1 (2010)

Congressional Budget Office, "Comparing the Compensation of Federal and Private-Sector Employees,” CBO Report, 2012.

DeNavas-Walt, Carmen, Bernadette D. Proctor, and Jessica C. Smith, “Income, Poverty, and Health Insurance Coverage in the United States: 2011,” Current Population Reports, P60-243, U.S. Census Bureau, Washington, DC, 2012.

Garrett, B., and Buettgens, M. (2011). Employer-Sponsored Insurance under Health Reform: Reports of Its Demise Are Premature. Working Paper, The Urban Institute.

Mach, A. (2013) Federal Employees Health Benefits Program (FEHBP): Available Health Insurance Options, CRS Report for Congress, Congressional Research Service.

Rubin, D. B. (1987), Multiple Imputation for Nonresponse in Surveys, New York: John Wiley \& Sons.

Shen, Y.-C., and Zuckerman, S. (2003). Why Is There State Variation In Employer-Sponsored Insurance? Health Affairs, 22(1), 241-251.

Sommers, J. P. Additional Imputations of Employer Information for the Insurance Component of the Medical Expenditure Panel Survey since 1996. Methodology Report No. 17. January 2007. Agency for Healthcare Research and Quality, Rockville, Md.

U.S. Census Bureau, Technical Paper No. 50, Alternative Methods for Valuing Selected In-Kind Transfer Benefits and Measuring Their Effect on Poverty, U.S. Government Printing Office, Washington, DC, 1982.

U.S. Census Bureau, Current Population Reports, Series P-60, No. 176-RD, Measuring the Effect of Benefits and Taxes on Income and Poverty: 1990, U.S. Government Printing Office, Washington, DC, 1991. 
Table 1: 2010 Percent of All Employer-Sponsored Health Insurance Policyholders by Employer And Employee Contributions

\begin{tabular}{|l|c|c|c|c|c|c|}
\hline \multirow{2}{*}{ Employee Contributions } & \multicolumn{4}{|c|}{ Employer Contributions } \\
\cline { 2 - 7 } & \multicolumn{2}{|c|}{ All } & \multicolumn{2}{c|}{ Some } & \multicolumn{2}{c|}{ None } \\
\cline { 2 - 7 } & Percent & $\begin{array}{c}\text { Standard } \\
\text { Error }\end{array}$ & Percent & $\begin{array}{c}\text { Standard } \\
\text { Error }\end{array}$ & Percent & $\begin{array}{c}\text { Standard } \\
\text { Error }\end{array}$ \\
\hline Zero & 14.2 & 0.12 & 20.2 & 0.13 & 1.5 & 0.03 \\
Greater than zero & 4.5 & 0.05 & 56.1 & 0.16 & 3.5 & 0.05 \\
\hline
\end{tabular}

Source: 2011 CPS ASEC 
Table 2: 2010 Median Non-Federal Employer Contribution for All Coverage Types by Employee Characteristic

(2010 U.S. Dollars)

\begin{tabular}{|c|c|c|c|c|c|}
\hline \multirow{2}{*}{ Characteristic } & \multicolumn{2}{|c|}{2010 MEPS-IC based } & \multicolumn{2}{|c|}{1977 NMCES-based } & \multirow{2}{*}{ t-statistic } \\
\hline & Median & $\begin{array}{c}\text { Standard } \\
\text { Error }\end{array}$ & Median & $\begin{array}{c}\text { Standard } \\
\text { Error }\end{array}$ & \\
\hline Total & 6,159 & 33 & 5,444 & 25 & 17.18 \\
\hline Class of Worker: & & & & & \\
\hline Private & 5,793 & 34 & 5,512 & 26 & 6.50 \\
\hline State/Local & 7,663 & 92 & 5,214 & 50 & 23.34 \\
\hline Sex: & & & & & \\
\hline Men & 6,353 & 49 & 6,108 & 41 & 3.86 \\
\hline Women & 5,960 & 44 & 4,758 & 34 & 21.80 \\
\hline Race and Ethnicity: & & & & & \\
\hline White Non-Hispanic & 6,189 & 40 & 5,503 & 30 & 13.75 \\
\hline Black Non-Hispanic & 5,948 & 73 & 4,541 & 65 & 14.35 \\
\hline Hispanic & 6,038 & 87 & 5,570 & 60 & 4.43 \\
\hline Age: & & & & & \\
\hline All 15 and over & 6,159 & 33 & 5,444 & 25 & 17.18 \\
\hline $15-18$ & 7,165 & 1,941 & 3,276 & 869 & 1.83 \\
\hline $19-25$ & 4,641 & 87 & 3,257 & 78 & 11.83 \\
\hline $26-44$ & 6,296 & 52 & 5,570 & 33 & 11.80 \\
\hline $45-64$ & 6,364 & 53 & 5,699 & 34 & 10.51 \\
\hline $65+$ & 5,590 & 120 & 4,766 & 119 & 4.88 \\
\hline Education: & & & & & \\
\hline No High School Diploma & 5,896 & 155 & 5,281 & 104 & 3.29 \\
\hline High School Diploma/Associate's Degree & 5,965 & 42 & 5,177 & 30 & 15.33 \\
\hline Bachelor's Diploma & 6,122 & 77 & 5,529 & 54 & 6.29 \\
\hline $\begin{array}{l}\text { Master's Degree/Professional/Ph.D } \\
\text { Family Income: As Percentage of } \\
\text { Income-Poverty Rate }\end{array}$ & 6,978 & 81 & 6,487 & 65 & 4.72 \\
\hline$<100$ IPR & 5,849 & 204 & 3,773 & 133 & 8.52 \\
\hline 100-199 IPR & 5,832 & 80 & 4,237 & 71 & 14.82 \\
\hline 200-299 IPR & 5,772 & 74 & 4,469 & 60 & 13.70 \\
\hline 300-399 IPR & 6,052 & 69 & 4,790 & 66 & 13.14 \\
\hline 400+ IPR & 6,358 & 46 & 6,218 & 37 & 2.36 \\
\hline
\end{tabular}

Source: 2011 CPS ASEC 


\begin{tabular}{|c|c|c|c|c|c|}
\hline \multirow[t]{2}{*}{ Characteristic } & \multicolumn{2}{|c|}{2010 MEPS-IC based } & \multicolumn{2}{|c|}{1977 NMCES-based } & \multirow{2}{*}{$\begin{array}{c}\mathbf{t}- \\
\text { statistic }\end{array}$} \\
\hline & Median & $\begin{array}{c}\text { Standard } \\
\text { Error }\end{array}$ & Median & $\begin{array}{c}\text { Standard } \\
\text { Error }\end{array}$ & \\
\hline \multicolumn{6}{|l|}{ Employer Contribution: } \\
\hline Entire Premium Paid by Employer & 5,327 & 51 & 5,230 & 44 & 1.44 \\
\hline Part of Premium Paid by Employer & 3,849 & 22 & 2,784 & 24 & 32.94 \\
\hline \multicolumn{6}{|l|}{ Class of Worker: } \\
\hline Private & 3,877 & 24 & 3,269 & 29 & 16.14 \\
\hline State/Local & 5,401 & 48 & 3,250 & 51 & 30.72 \\
\hline \multicolumn{6}{|l|}{ Location (Census Region): } \\
\hline New England & 4,407 & 103 & 4,260 & 73 & 1.16 \\
\hline Mid-Atlantic & 4,271 & 60 & 3,682 & 59 & 6.98 \\
\hline East-North-Central & 4,016 & 61 & 3,788 & 68 & 2.51 \\
\hline West-North-Central & 3,986 & 66 & 3,290 & 58 & 7.91 \\
\hline South Atlantic & 4,064 & 43 & 2,368 & 53 & 24.63 \\
\hline East-South-Central & 3,935 & 68 & 1,992 & 92 & 16.93 \\
\hline West-South-Central & 3,881 & 77 & 2,014 & 78 & 17.01 \\
\hline Mountain & 4,058 & 77 & 3,001 & 84 & 9.32 \\
\hline Pacific & 4,267 & 45 & 4,198 & 65 & 0.89 \\
\hline \multicolumn{6}{|l|}{ Industry: } \\
\hline Agriculture, forestry, fishing, and hunting & 4,326 & 724 & 2,386 & 278 & 2.50 \\
\hline Mining & 4,135 & 427 & 5,681 & 519 & 2.30 \\
\hline Construction & 3,977 & 105 & 4,132 & 111 & 1.01 \\
\hline Manufacturing & 3,599 & 53 & 4,109 & 58 & 6.52 \\
\hline Wholesale and Retail & 3,565 & 45 & 2,841 & 44 & 11.42 \\
\hline Transportation and Utilities & 3,936 & 87 & 4,244 & 95 & 2.39 \\
\hline Information & 4,226 & 107 & 4,004 & 144 & 1.23 \\
\hline Financial Activities & 4,068 & 61 & 3,079 & 63 & 11.22 \\
\hline Professional and Business Services & 3,786 & 48 & 3,059 & 61 & 9.37 \\
\hline Education and Health Services & 4,720 & 42 & 3,013 & 40 & 29.43 \\
\hline Leisure and Hospitality & 3,479 & 102 & 2,115 & 81 & 10.50 \\
\hline Other Services & 4,352 & 111 & 2,773 & 102 & 10.47 \\
\hline Public Administration & 5,476 & 90 & 3,784 & 101 & 12.48 \\
\hline \multicolumn{6}{|l|}{ Firmsize: } \\
\hline$<10$ Employees & 4,309 & 92 & 3,417 & 99 & 6.59 \\
\hline 10-24 Employees & 3,981 & 59 & 3,434 & 46 & 7.33 \\
\hline 25-99 Employees & 3,856 & 65 & 3,114 & 76 & 7.41 \\
\hline 100-499 Employees & 4,088 & 53 & 3,234 & 59 & 10.72 \\
\hline 500-999 Employees & 4,060 & 93 & 3,166 & 81 & 7.23 \\
\hline 1000+ Employees & 4,163 & 28 & 3,239 & 35 & 20.74 \\
\hline Source: 2011 CPS ASEC & & & & & \\
\hline
\end{tabular}




\begin{tabular}{|c|c|c|c|c|c|}
\hline \multirow[t]{2}{*}{ Characteristic } & \multicolumn{2}{|c|}{2010 MEPS-IC based } & \multicolumn{2}{|c|}{1977 NMCES-based } & \multirow{2}{*}{$\begin{array}{c}\mathrm{t}- \\
\text { statistic }\end{array}$} \\
\hline & Median & $\begin{array}{l}\text { Standard } \\
\text { Error }\end{array}$ & Median & $\begin{array}{c}\text { Standard } \\
\text { Error }\end{array}$ & \\
\hline \multicolumn{6}{|l|}{ Employer Contribution: } \\
\hline Entire Premium Paid by Employer & 9,815 & 2 & 9,217 & 46 & 12.90 \\
\hline Part of Premium Paid by Employer & 8,563 & 45 & 6,639 & 23 & 37.92 \\
\hline \multicolumn{6}{|l|}{ Class of Worker: } \\
\hline Private & 8,694 & 46 & 7,120 & 28 & 29.07 \\
\hline State/Local & 9,787 & 3 & 6,589 & 48 & 66.38 \\
\hline \multicolumn{6}{|l|}{ Location (Census Region): } \\
\hline New England & 9,778 & 5 & 8,274 & 83 & 18.01 \\
\hline Mid-Atlantic & 9,773 & 4 & 7,510 & 71 & 31.81 \\
\hline East-North-Central & 9,000 & 132 & 7,638 & 45 & 9.80 \\
\hline West-North-Central & 8,568 & 112 & 7,019 & 50 & 12.64 \\
\hline South Atlantic & 8,701 & 121 & 5,826 & 50 & 22.00 \\
\hline East-South-Central & 7,985 & 238 & 5,552 & 86 & 9.60 \\
\hline West-South-Central & 8,349 & 145 & 5,604 & 70 & 17.04 \\
\hline Mountain & 8,416 & 134 & 6,544 & 93 & 11.48 \\
\hline Pacific & 9,337 & 101 & 8,051 & 63 & 10.79 \\
\hline \multicolumn{6}{|l|}{ Industry: } \\
\hline Agriculture, forestry, fishing, and hunting & 8,647 & 829 & 5,473 & 199 & 3.72 \\
\hline Mining & 9,453 & 224 & 9,348 & 217 & 0.34 \\
\hline Construction & 8,196 & 199 & 7,866 & 87 & 1.52 \\
\hline Manufacturing & 8,558 & 102 & 7,874 & 42 & 6.19 \\
\hline Wholesale and Retail & 7,916 & 111 & 6,577 & 55 & 10.81 \\
\hline Transportation and Utilities & 9,345 & 142 & 7,987 & 74 & 8.45 \\
\hline Information & 9,670 & 176 & 8,153 & 137 & 6.82 \\
\hline Financial Activities & 9,001 & 133 & 6,814 & 73 & 14.37 \\
\hline Professional and Business Services & 8,750 & 125 & 7,029 & 71 & 12.01 \\
\hline Education and Health Services & 9,754 & 4 & 6,410 & 42 & 78.81 \\
\hline Leisure and Hospitality & 7,869 & 232 & 5,437 & 107 & 9.52 \\
\hline Other Services & 8,629 & 234 & 6,288 & 152 & 8.39 \\
\hline Public Administration & 9,788 & 6 & 7,187 & 72 & 36.03 \\
\hline \multicolumn{6}{|l|}{ Firmsize: } \\
\hline$<10$ Employees & 8,193 & 190 & 6,967 & 91 & 5.81 \\
\hline 10-24 Employees & 8,379 & 106 & 6,952 & 71 & 11.18 \\
\hline 25-99 Employees & 8,673 & 177 & 6,869 & 89 & 9.12 \\
\hline 100-499 Employees & 8,930 & 89 & 6,997 & 50 & 18.92 \\
\hline 500-999 Employees & 9,002 & 163 & 6,916 & 69 & 11.74 \\
\hline 1000+ Employees & 9,354 & 70 & 7,069 & 34 & 29.47 \\
\hline Source: 2011 CPS ASEC & & & & & \\
\hline
\end{tabular}


Table 5: 2010 Median Employer Contribution by State (2010 U.S. Dollars)

\begin{tabular}{|c|c|c|c|c|c|}
\hline \multirow{2}{*}{ Characteristic } & \multicolumn{2}{|c|}{2010 MEPS-IC based } & \multicolumn{2}{|c|}{1977 NMCES-based } & \multirow{2}{*}{ t-statistic } \\
\hline & Median & Standard Error & Median & Standard Error & \\
\hline Alabama & 5,811 & 326 & 4,121 & 169 & 4.61 \\
\hline Alaska & 8,713 & 187 & 6,144 & 142 & 10.96 \\
\hline Arizona & 5,362 & 201 & 5,335 & 185 & 0.10 \\
\hline Arkansas & 4,168 & 233 & 3,273 & 319 & 2.26 \\
\hline California & 6,273 & 92 & 6,687 & 70 & 3.58 \\
\hline Colorado & 5,990 & 148 & 5,099 & 135 & 4.44 \\
\hline Connecticut & 7,878 & 276 & 7,134 & 136 & 2.42 \\
\hline Delaware & 7,233 & 277 & 4,808 & 157 & 7.61 \\
\hline District of Columbia & 5,180 & 196 & 4,155 & 250 & 3.22 \\
\hline Florida & 5,547 & 126 & 4,311 & 81 & 8.25 \\
\hline Georgia & 6,274 & 312 & 4,796 & 120 & 4.42 \\
\hline Hawaii & 4,822 & 143 & 5,609 & 93 & 4.62 \\
\hline Idaho & 6,517 & 267 & 4,993 & 233 & 4.30 \\
\hline Illinois & 5,983 & 132 & 6,191 & 105 & 1.23 \\
\hline Indiana & 6,651 & 353 & 6,333 & 194 & 0.79 \\
\hline Iowa & 6,085 & 202 & 5,585 & 184 & 1.83 \\
\hline Kansas & 5,499 & 230 & 5,282 & 136 & 0.81 \\
\hline Kentucky & 5,788 & 261 & 4,144 & 218 & 4.84 \\
\hline Louisiana & 6,592 & 469 & 4,380 & 275 & 4.07 \\
\hline Maine & 6,645 & 227 & 6,118 & 129 & 2.02 \\
\hline Maryland & 6,705 & 261 & 4,860 & 120 & 6.43 \\
\hline Massachusetts & 7,126 & 364 & 6,961 & 251 & 0.37 \\
\hline Michigan & 6,878 & 286 & 6,815 & 168 & 0.19 \\
\hline Minnesota & 6,247 & 336 & 5,708 & 141 & 1.48 \\
\hline Mississippi & 5,195 & 291 & 3,947 & 254 & 3.24 \\
\hline Missouri & 5,912 & 216 & 5,815 & 211 & 0.32 \\
\hline Montana & 6,413 & 216 & 4,562 & 226 & 5.91 \\
\hline Nebraska & 6,198 & 147 & 5,376 & 174 & 3.61 \\
\hline Nevada & 5,797 & 167 & 5,262 & 136 & 2.48 \\
\hline New Hampshire & 7,699 & 291 & 6,653 & 102 & 3.39 \\
\hline New Jersey & 7,424 & 327 & 6,657 & 108 & 2.23 \\
\hline New Mexico & 6,277 & 442 & 5,378 & 315 & 1.66 \\
\hline New York & 6,907 & 193 & 6,053 & 98 & 3.95 \\
\hline North Carolina & 5,558 & 139 & 4,100 & 121 & 7.91 \\
\hline North Dakota & 5,708 & 231 & 5,629 & 133 & 0.30 \\
\hline Ohio & 6,233 & 189 & 6,286 & 105 & 0.25 \\
\hline Oklahoma & 5,494 & 141 & 4,077 & 125 & 7.53 \\
\hline Oregon & 6,497 & 261 & 6,038 & 124 & 1.59 \\
\hline
\end{tabular}

Table continues on next page. 


\begin{tabular}{|l|c|c|c|c|c|}
\hline \multirow{2}{*}{\multicolumn{1}{|c|}{ Characteristic }} & \multicolumn{2}{|c|}{ 2010 MEPS-IC based } & \multicolumn{2}{c|}{ 1977 NMCES-based } & \multirow{2}{*}{ t-statistic } \\
\cline { 2 - 5 } & Median & Standard Error & Median & Standard Error & \\
\hline Pennsylvania & 6,482 & 176 & 5,708 & 110 & 3.73 \\
Rhode Island & 7,264 & 257 & 7,158 & 176 & 0.34 \\
South Carolina & 5,401 & 197 & 4,095 & 183 & 4.86 \\
South Dakota & 5,264 & 264 & 5,091 & 148 & 0.57 \\
Tennessee & 5,188 & 157 & 3,909 & 109 & 6.70 \\
Texas & 5,646 & 93 & 4,352 & 74 & 10.88 \\
Utah & 6,565 & 417 & 5,569 & 259 & 2.03 \\
Vermont & 6,864 & 408 & 6,325 & 94 & 1.29 \\
Virginia & 6,027 & 239 & 4,720 & 199 & 4.19 \\
Washington & 6,317 & 263 & 6,022 & 205 & 0.88 \\
West Virginia & 7,288 & 355 & 4,728 & 202 & 6.27 \\
Wisconsin & 7,221 & 312 & 6,333 & 135 & 2.61 \\
Wyoming & 6,778 & 245 & 4,969 & 189 & 5.85 \\
\hline
\end{tabular}

Source: 2011 CPS ASEC 
Table 6: 2010 Median Federal Contribution by Employee Characteristic (2010 U.S. Dollars)

\begin{tabular}{|c|c|c|c|c|c|}
\hline \multirow[b]{2}{*}{ Characteristic } & \multicolumn{2}{|c|}{2010 MEPS-IC based } & \multicolumn{2}{|c|}{1977 NMCES-based } & \multirow{2}{*}{$\begin{array}{c}\text { t- } \\
\text { statistic }\end{array}$} \\
\hline & Median & $\begin{array}{c}\text { Standard } \\
\text { Error }\end{array}$ & Median & $\begin{array}{c}\text { Standard } \\
\text { Error }\end{array}$ & \\
\hline Total Federal Employees & 8,276 & 244 & 9,006 & 303 & 1.88 \\
\hline Sex: & & & & & \\
\hline Men & 8,728 & 265 & 9,040 & 9 & 1.18 \\
\hline Women & 7,268 & 448 & 5,653 & 83 & 3.54 \\
\hline \multicolumn{6}{|l|}{ Race and Ethnicity: } \\
\hline White Non-Hispanic & 8,601 & 327 & 9,023 & 10 & 1.29 \\
\hline Black Non-Hispanic & 6,922 & 516 & 5,668 & 59 & 2.41 \\
\hline Hispanic & 7,944 & 758 & 7,343 & 1,899 & 0.29 \\
\hline \multicolumn{6}{|l|}{ Education: } \\
\hline No High School Diploma & 4,997 & 1,579 & 5,524 & 1,244 & 0.26 \\
\hline High School Diploma/Associate's Degree & 8,309 & 382 & 9,008 & 505 & 1.10 \\
\hline Bachelor's Diploma & 7,914 & 568 & 9,006 & 572 & 1.35 \\
\hline Master's Degree/Professional/Ph.D & 8,720 & 304 & 9,012 & 332 & 0.65 \\
\hline \multicolumn{6}{|l|}{ Location (Census Region): } \\
\hline New England & 9,407 & 688 & 9,059 & 682 & 0.36 \\
\hline Mid-Atlantic & 8,264 & 1,783 & 7,427 & 1,799 & 0.33 \\
\hline East-North-Central & 8,577 & 905 & 8,818 & 1,556 & 0.13 \\
\hline West-North-Central & 8,770 & 462 & 9,056 & 24 & 0.62 \\
\hline South Atlantic & 8,010 & 525 & 7,992 & 1,716 & 0.01 \\
\hline East-South-Central & 8,588 & 546 & 9,041 & 91 & 0.82 \\
\hline West-South-Central & 8,106 & 571 & 8,377 & 1,834 & 0.14 \\
\hline Mountain & 8,903 & 844 & 9,045 & 19 & 0.17 \\
\hline Pacific & 7,629 & 619 & 6,386 & 2,839 & 0.43 \\
\hline \multicolumn{6}{|l|}{ Type of Coverage: } \\
\hline Single Coverage & 4,296 & 72 & 4,389 & 4 & 1.29 \\
\hline Family Coverage & 9,809 & 4 & 9,127 & 4 & 112.15 \\
\hline
\end{tabular}

Source: 2011 CPS ASEC 
Table 7: 2010 Moments of All Non-Federal Employer Contribution Distribution by Coverage Type and Top-Code Status (2010 U.S. Dollars)

\begin{tabular}{|l|c|c|c|c|c|c|c|c|}
\hline \multirow{4}{*}{\begin{tabular}{c}
\multirow{2}{*}{$\begin{array}{c}\text { Coverage } \\
\text { Type }\end{array}$} \\
\cline { 2 - 9 }
\end{tabular}} & \multicolumn{4}{|c|}{ Top-Coded } & \multicolumn{4}{c|}{ Not Top-Coded } \\
\cline { 2 - 8 } & Mean & $\begin{array}{c}\text { Standard } \\
\text { Error }\end{array}$ & $\begin{array}{c}\text { Standard } \\
\text { Deviation }\end{array}$ & $\begin{array}{c}\text { Standard } \\
\text { Error }\end{array}$ & Mean & $\begin{array}{c}\text { Standard } \\
\text { Error }\end{array}$ & $\begin{array}{c}\text { Standard } \\
\text { Deviation }\end{array}$ & $\begin{array}{c}\text { Standard } \\
\text { Error }\end{array}$ \\
\hline All & 6,346 & 19 & 3,598 & 12 & 7,210 & 28 & 5,436 & 28 \\
Single & 4,246 & 20 & 2,543 & 20 & 4,252 & 20 & 2,568 & 21 \\
Plus-One & 7,210 & 28 & 3,229 & 30 & 7,464 & 47 & 4,289 & 47 \\
Family & 8,555 & 20 & 2,539 & 26 & 10,696 & 40 & 5,159 & 42 \\
\hline
\end{tabular}

Source: 2011 CPS ASEC 